\title{
SOBRE LA RELACIÓN DEL DERECHO PENAL CON EL DERECHO PROCESAL PENAL
}

\section{THE RELATIONSHIP BETWEEN CRIMINAL LAW AND CRIMINAL PROCEDURAL LAW}

\author{
Juan Sebastián Vera Sánchez*
}

\begin{abstract}
RESUMEN: Este trabajo propone un elemento de análisis metodológico del Derecho procesal penal, a partir de los inconvenientes observados de la relación actual entre Derecho penal y Derecho procesal penal, caracterizada de separación o instrumentalización entre ambas áreas.
\end{abstract}

Palabras clave: Sincronismo metodológico-Derecho penal-Derecho procesal penal-Metodología del Derecho procesal penal.

ABSTRACT: This essay suggest a methodological analysis element for criminal procedure, based on the observed problems of the current relationship between Criminal law and Criminal procedural law, characterized by a vision of separation and instrumentality between both areas.

Key words: Methodological synchronism-Criminal Law-Procedure Law-Methodology of Procedure law.

\section{INTRODUCCIÓN}

Los estudios que se han realizado -recientemente- respecto a cómo el juez decide una cuestión penal apuntan a que dicho proceso es un todo continuo de naturaleza bidireccional ${ }^{1}$. En efecto, el juez que decide sobre un hecho posiblemente delictivo no se desdobla para, primero, analizar el asunto desde una perspectiva dogmático penal y, luego, aplicar los principios de la doctrina procesal penal. A mi modo de ver, la decisión definitiva sobre absolución o condena se realiza en el marco de un proceso penal institucionalizado que, a su vez, es un elemento del sistema de justicia penal. Desde esta perspectiva, entonces, la interpretación jurídica respecto de las cuestiones procesales penales no solo deberían considerar los criterios técnicos autónomos del Derecho procesal penal -si se puede decir que se han identificado completamente atendida la "juventud” de esta área del Derecho-, sino

\footnotetext{
* Doctor en Derecho Universidad de Barcelona. Profesor de Derecho penal, Derecho procesal penal y Derecho probatorio en la Universidad Austral de Chile. Dirección postal: Facultad de Ciencias Jurídicas y Sociales, Universidad Austral de Chile, Isla Teja s/n, Valdivia, Chile. Dirección electrónica: juan.vera@uach.cl. Este trabajo se enmarca en el proyecto de investigación "Teoría del delito y proceso penal: ¿Dos instrumentos conciliables? (DER2014-59247-R) del Ministerio de Economía, Industria y Competitividad del Gobierno de España, cuyos investigadores principales son la Dra Mirentxu Corcoy y el Dr. Victor Gómez, y en el cual el autor es miembro del equipo de investigación. Quisiera expresar mi gratitud a los profesores Dra. Mirentxu Corcoy Bidasolo y al Dr. Jordi Nieva Fenoll por sus importantes comentarios para este trabajo.

1 SimON (2004) p. 522. Sobre la valoración de la prueba como proceso abductivo, véase, LARROUCAU (2012) pp. 798 ss.
} 
también su incidencia en la operatividad, validez, y eficacia del sistema de justicia penal en su conjunto. Es decir, las cuestiones procesales penales también, en su análisis, deberían considerar elementos metodológicos vinculados con los efectos de las cuestiones procesales desde el punto de vista sistemático de la justicia penal.

Lo anterior se ve dificultado por dos características asumidas de forma tradicional sobre la relación entre Derecho penal y Derecho procesal penal, a saber: a) la existencia de una férrea separación entre ambas áreas y, b) la naturaleza instrumental que el Derecho procesal penal presentaría respecto del Derecho penal.

En este sentido, se señala que los orígenes de la división entre estas dos áreas del enjuiciamiento criminal se remonta al periodo de codificación de la Ilustración cuando se asumió con claridad que normas procesales y penales debían consignarse en cuerpos legales distintos ${ }^{2}$. Esto difería de lo que ocurría en la antigüedad donde ambos aspectos eran tratados en un cuerpo único ${ }^{3}$. Ejemplo de esto último es la "Constitutio Criminalis Carolina" la Ley de Responsabilidad Penal Juvenil alemanas, las "Siete Partidas" de Alfonso X, el Sabio. En la doctrina también es posible encontrar ejemplos de tratamiento conjunto de aspectos procesales y penales como en "Le practica nova" de Carpzovio (1635), "Lehrbuch" de Feuerbach (1801) ${ }^{6}$, "Elementa Iuris Crim" de Carmignani ${ }^{7}$. De hecho, puede observarse que en los países donde no ha tenido importancia el fenómeno de la codificación, la separación entre Derecho penal y Derecho procesal penal no es tan rígida. Valga como ejemplo la situación que muestran algunos de los países del common law ${ }^{8}$.

En relación con la naturaleza instrumental que presentaría el Derecho procesal penal respecto del Derecho penal, ello podría basarse en aspectos propios de la evolución de la ciencia jurídica, como el entendimiento de la corriente formalista del Derecho que, unida a circunstancias históricas concretas, ha impedido que la interpretación de normas procesales -so pena de considerarse irracionales o ilógicas ${ }^{9}$ - salgan de los límites estrictos de la interpretación lógico-formal de carácter procedimentalista. Todo ello, aun cuando se entienda -de manera correcta, en mi opinión- que la corriente formalista no se refiere históricamen-

\footnotetext{
2 Ragués i Vallès (2004) p. 129; Díaz Cantón (2005) p. 4.

3 En este sentido, Antolisei (1988) p. 10; Fenizia (1977) p. 4; Maggiore (1949) p. 43; Hassemer y Muñoz Conde (1989) p. 122; Jescheck y Weigend (2002) p.18; Maurach y Zipf (1994) p. 31; Mezger (1935) p 33; Jiménez de Asúa (1964) p. 67; Gómez Orbaneja (1947) p. 40.

4 Mezger (1935) p. 33: Mezger (1958) p. 30; Welzel (1976) p. 23; Baumann (1973) p. 6.

Hassemery Muñoz Conde (1989) p. 122; Jescheck Y Weigend (2002) p. 18; Roxin (1997) p. 46.

Mezger (1935) p. 33; Feuerbach (1989) p. 48.

Maggiore (1949) p. 43. Más actuales son el tratamiento conjunto en Longhi (1911), p. 647 y 927; FrosaLI (1958).

8 Ragués i Vallès (2004) p. 130. Este autor señala, que en los países del common law no solo forman parte del concepto "defence" las causales de justificación o causales de exclusión de la culpabilidad, sino también la prescripción, la inmunidad diplomática, el delito provocado o doble enjuiciamiento.

9 Por ejemplo, Mazzarese (1996) p. 203: “De esta forma, no es sorprendente que cualquiera que se atreva a plantear los problemas con que se enfrenta la teoría lógico-deductiva de las decisiones judiciales sea inmediatamente acusado como irracionalista y condenado como un defensor del decisionismo y del subjetivismo arbitrario del poder judicial”.
} 
te a una descripción autómata de la labor del juez, sino más bien constituya un enunciado prescriptivo acerca de cómo ha de desarrollar dicha labor ${ }^{10}$.

Respecto al cuestionamiento de la interpretación lógico-formal de las normas y el irracionalismo, solo por citar un caso conocido, la opinión del mismísimo Kelsen -respecto al Derecho y la lógica ${ }^{11}$ - fue calificada como parte de las corrientes irracionalistas normativas ("Normenirrationalismus") por Weinberger ${ }^{12}$.

En los países del civil law la codificación generó un proceso de especialización dentro del Derecho, lo que ha ocasionado un efecto centrífugo de disociación ${ }^{13}$. El nacimiento de la dogmática penal moderna -en el marco de la Ilustración ${ }^{14}-$, pudo haber ayudado a la diferenciación entre el Derecho material y el Derecho procesal. Ello, por cuanto -con anterioridad a esa época-, la ciencia penal solo se reducía al análisis de casos, comentarios de textos, sin siquiera independizarse completamente del Derecho canónico y del Derecho civil $^{15}$. En este contexto la doctrina penal "ganó tiempo" respecto al Derecho civil y al Derecho procesal, pues estos se incorporaron más tarde al proceso de codificación ${ }^{16}$.

La distinción entre Derecho penal y Derecho procesal penal ha sido fruto de una larga evolución ${ }^{17}$ y desarrollo, en la cual la especialización y separación se muestra como el principal objetivo. Sin embargo, dicha separación no ha sido óbice -sino más bien presupuesto-, de la vinculación necesaria entre estas áreas del ordenamiento jurídico. Ello, en cuanto no puede desconocerse el hecho que razones de oportunidad lingüística y científica llevan siempre a considerar adecuada la perspectiva instrumental del proceso penal ${ }^{18}$, aunque no se esté de acuerdo con ello.

Ahora, todo lo anterior plantea si sigue siendo correcta y adecuada -atendida la significación social del proceso penal y del sistema de justicia penal- la separación científica irrestricta entre Derecho penal y Derecho procesal penal, por un lado, y su vinculación por medio de una relación de instrumentalización, por otro.

Vamos a poner un ejemplo: supongamos que el legislador decide declarar imprescriptibles los delitos cometidos contra menores de edad. ¿La imprescriptibilidad es un

10 En este sentido, Ortiz de Urbina (2007) p. 43: "Cuando la tesis de la sujeción del juez se entiende como una tesis prescriptiva, en lugar de una tesis descriptiva (es decir, se sabe que el juez no está atado, pero se entiende que debe actuar como si lo estuviera), esta ya no es tan ingenua ni tan primitiva”. En el mismo sentido, SCHAUER (1988) p. 521: "Formalism in this sense is not the denial of choice by the judge, as above, but the denial of choice to the judge. To be formalistic, it is said, is to be enslaved by mere marks on a printed page."

11 Cfr. Kelsen y Klug (1988) pp. 92 ss.

12 Weinberger (1981) p. 166. En el original: „Der rational-analytische und logisierende Zutritt Kelsen zur Rechtstheorie, der ihn zu einem der berühmtesten Strukturtheoretiker des Rechts machte, war sukzessive eine Reihe von Erschütterungen ausgesetzt, die Kelsen schlie lich zur Überzeugung brachte, da es im Bereich der Normen keine logischen Beziehungen und kein Folgern gibt. Als konsequente Forscherpersönlichkeit versuchte nun Kelsen, seine Lehre im Geiste des Normenirrationalismus umzubauen".

13 García Pablos (2005) p. 124.

14 Binder (2001) p. 780.

15 Morillas Cuevas (1990) p. 13.

16 Bacigalupo (1999) p. 90.

17 Antolisei (1988) p. 10; Fenizia (1977) p. 4.

18 Pagliaro (2000) p. 17. 
aspecto "sustantivo"? ¿La imprescriptibilidad es una cuestión "procesal" referente a la mera procedibilidad? En este sentido, si la imprescriptibilidad fuera "sustantiva”, entonces solo podría ser aplicable a los hechos cometidos durante su vigencia, salvo que su aplicación retroactiva fuera favorable a reo. Por el contrario, si la imprescriptibilidad se considera una institución "procesal", entonces podría, por ejemplo, aplicarse a hechos ya cometidos, que no se hubiesen juzgado o se estuvieren juzgando, pero sobre los cuales no ha recaído sentencia definitiva con autoridad de cosa juzgada.

En otro caso, si las normas procesales fueran meramente instrumentales no debería tener ninguna importancia el hecho de haberse cometido una legítima defensa, que se pudiera establecer claramente, por ejemplo, para la aplicación o no de la medida cautelar de prisión preventiva. En este sentido, la palabra "delito" del artículo 140 letra a) del Código Procesal Penal no tendría por qué incluir una ponderación acerca de las causales de justificación concurrentes que deben ser establecidas y reconocidas en momentos posteriores del juicio, y no en una etapa temprana del procedimiento como cuando se decreta una medida cautelar. Ahora, si las normas procesales tuvieran otras funcionalidades más allá que las meramente adjetivas, su aplicación tendría que considerar los efectos perjudiciales de someter a una persona que ha actuado lícitamente a una medida cautelar de gran intensidad como la prisión preventiva. En otro sentido, si se adopta una visión de sistema de la justicia penal y se considera a sus elementos como subsistemas de organización social ${ }^{19}$-como puede desprenderse de las teorías de la concepción dinámica del Derecho ${ }^{20}$-ha de existir una necesaria vinculación entre ambas a través de ciertas circunstancias de entrada y salida que dan estructura al sistema, provocan su regeneración, y canalizan la influencia recíproca con la sociedad.

Todo lo anterior cuestiona las concepciones tradicionales de la relación entre Derecho penal y Derecho procesal penal, sobre las cuales ahondaré en la primera parte de este trabajo. En la segunda parte realizaré algunos comentarios sobre ciertos elementos que pueden ayudar a una mejor comprensión de la relación entre estas dos áreas, considerando que el Derecho procesal penal es un elemento más del sistema de justicia criminal. En suma, con este trabajo busco describir el análisis de la relación entre normas penales y procesales, cuestionando la visión tradicional al respecto y sugiriendo una relación de sincronismo o retroalimentación entre dichas normas, como criterio que permite una mejor resolución de los conflictos generados en la aplicación de dichas normas.

\section{CRITERIOS TRADICIONALES PARA DISTINGUIR ENTRE DERECHO PENAL Y DERECHO PROCESAL PENAL}

La diferenciación entre Derecho penal y Derecho procesal penal iría más allá de una mera reivindicación científica y/o metodológica. Se suele decir que tendría efectos prácti-

\footnotetext{
19 En relación con la asunción de que el Derecho puede ser considerado un subsistema, véase, Friedman (1975) p. 10 s.

20 Cfr., Sánchez de la Torre (1965) pp. 317 ss.
} 
cos. Por ello resulta ilustrativo revisar, de manera esquemática, los criterios en los cuales se ha fundamentado esta diferenciación. También, en cuanto nos permite revisar la pertinencia y validez de los mismos.

\subsection{El criterio de la “aplicación judicial del Derecho penal”}

Es posible encontrar posiciones que dan primacía al Derecho procesal penal en relación con la norma sustantiva. La razón de ello es la consideración del proceso penal como único camino o medio por el cual podría producirse un "derecho penal judicial"21. Desde el punto de vista práctico, eso sería lo más importante. Así, nadie puede negar que la norma penal se hace más "visible" cuando se inicia un procedimiento penal para la persecución de una conducta constitutiva de delito. Y que, por el contrario, desde un punto de vista social, se produce un "desvanecimiento" público de la reprochabilidad penal de la conducta cuando el Ministerio Público decide, por ejemplo, no iniciar una investigación. La importancia de la configuración del proceso penal para que la norma penal despliegue todos sus efectos jurídicos y políticos ha llevado a sostener por parte de la doctrina que el proceso penal puede ser considerado, bajo ciertos supuestos, una variable político-criminal ${ }^{22}$.

Así, lo único importante para este enfoque es que la norma penal logre entrar al "engranaje" del procedimiento penal, pues pareciere ser que esa es su principal utilidad institucional. Ahora, un aspecto positivo de esta concepción es que cuestionaría la validez de la tesis de la "instrumentalización" del proceso penal, en cuanto la única forma de manifestación del Derecho penal es la generada por y en el proceso penal. Sin embargo, esta posición ignora la importancia de los efectos de la mera existencia de la norma penal, aun cuando siempre ha de estar vinculada a su aplicación potencial por medio del proceso. En efecto, si solo se considerara el derecho penal judicial, tendríamos que llegar a la conclusión que la pena no sirve, pues no previene ni intimida, de momento que los procesos penales se sustancian conforme a un acto que infringe la norma penal. Por mi parte, no creo acertado juzgar la efectividad de la pena como consecuencia jurídica de la norma penal a través de su infracción. Por el contrario, la capacidad que presente el sistema de justicia penal para hacer que los ciudadanos no cometan delitos se ha de juzgar sobre la base de innumerables conductas que se adecuan a las normas penales y que, por tanto, no dan lugar a un proceso penal.

En otro sentido, aunque el proceso penal presenta algunos reductos "morales" propios, sin duda también se hace partícipe de la decisión de protección de ciertos intereses o valores por parte de la norma penal al ser la principal vía de conexión entre la norma penal y el ciudadano en concreto.

Con todo, dar una primacía irrestricta a la norma procesal penal sobre la norma penal tampoco es el camino adecuado, pues el efecto de las normas procesales, aun cuando pueda considerarse como "judicializador" de las normas penales, no puede conseguirse sin estas últimas. Desde esta perspectiva, la existencia y aplicación de ambos tipos de normas

21 Cfr., Garafoli (2006) pp. 1 ss. En contra, Baumann (1973) p. 6.

22 Cfr., Vera (2015) pp. 1 ss. 
jurídicas en una relación recíprocamente complementaria permiten que el sistema de justicia penal despliegue todos sus efectos.

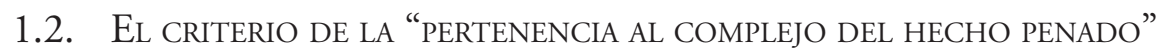

En la actualidad se ha recurrido al criterio de pertenencia de la circunstancia al "complejo del hecho penado" como criterio diferenciador propio de las normas penales ${ }^{23}$. Es decir, si la institución en estudio pertenece al complejo del hecho, entonces, sus efectos e interpretación quedarán circunscritos al Derecho penal. De lo contrario, deberán ser aplicables los criterios de interpretación del Derecho procesal penal.

No obstante la claridad de la formulación anterior, es necesario destacar que es posible constatar excepciones en ambos sentidos. Por un lado, instituciones no pertenecientes a este complejo del hecho y que, sin embargo, son consideradas circunscritas al Derecho penal $^{24}$. Del mismo modo es posible encontrar situaciones especiales en el caso inverso ${ }^{25}$.

Por ejemplo, el sobreseimiento pareciere ser en principio una institución procesal que no se vincularía con el complejo del hecho, pues se trata de un pronunciamiento en la fase intermedia del proceso penal donde aún no ha habido fase de Juicio Oral. Es una forma de suspensión o terminación anticipada del procedimiento. Piénsese por ejemplo en el caso de sobreseimiento temporal por falta de prueba. Sin embargo, el sobreseimiento presenta una gran cercanía con el complejo del hecho. Y en este sentido, puede considerarse una concreción del Derecho penal sustantivo en una fase anterior a la de Juicio Oral, precisamente porque en el procedimiento se sobresee definitivamente cuando el hecho no es constitutivo de delito, si el imputado estuviere exento de responsabilidad criminal en virtud del artículo 10 del Código penal, si estuviere extinguida su responsabilidad penal, etc. (art. 250 Código procesal penal). Podríamos decir que en estos casos hay un juicio de valoración penal de la conducta. Esta conexión del sobreseimiento con el complejo del hecho puede graficarse, quizás, indirectamente, en que el pronunciamiento referido al sobreseimiento definitivo produce cosa juzgada (art. 251 Código procesal penal), al igual que el pronunciamiento sobre el fondo del caso.

De esta forma, dicho criterio diferenciador no es eficaz en su tarea de distinguir normas procesales y penales. Ello, en cuanto las innumerables excepciones terminan por desvirtuar la naturaleza y potencialidad de la formulación de la pertenencia a dicho complejo como categoría distintiva.

Al margen de todo ello, incluso los mismos cuestionamientos a una noción ontológica de "hecho", desvinculado de toda norma jurídica, sirven, también, para sostener que

\footnotetext{
23 Roxin (1997) p. 985. En este sentido en Alemania, Stratenwerth (2005) p. 110; Welzel (1976) p. 89; Baumann (1973) pp. 4 s. En este sentido, en España, Octavio de Toledo y Ubieto y Huerta Tocildo (1986) pp. 406 ss; Gómez Orbaneja (1947) pp. 34, 40 y 41; En una visión que podría ser antecesora de esta teoría, Manzini (1941) p. 125, considera que la diferencia hay que verla en los campos de regulación. La potestad punitiva del Estado (pretensión punitiva o pena) viene regulada por el Derecho penal. La regulación que atiende al contenido formal del proceso es competencia del Derecho procesal penal. En este último sentido, FrosaLI (1958) p.6., considera que, usando la terminología de Kant, las normas penales se refieren a una obligación (imperativo categórico), mientras que las procesales penales se refieren a "cargas".

24 Wolter (2004) p. 63; Frisch (2004) p. 216.

25 Díaz Cantón (2005) pp. 2 ss; Freund (2004) pp. 94 y 101.
} 
no es posible concebir una separación tajante y sin zonas grises entre normas penales y procesales. Ello, si se adopta una posición tradicional que asocia los aspectos de hecho de la decisión judicial con los aspectos procedimentales, distinguiéndolos de las consideraciones de derecho o del fondo del asunto que en este caso se corresponderían con la norma penal, sustancial o material. Por eso se ha dicho -reviviendo un poco la discusión-, que no existen hechos, por un lado, y leyes por otro, sino un solo proceso de selección simultánea en donde ambos se interrelacionan ${ }^{26}$.

\subsection{El CRITERIO DEL “MERECIMIENTO" Y “NECESIDAD DE PENA"}

Se ha intentado situar la diferencia entre normas penales y procesales atendiendo a los criterios de merecimiento y necesidad de pena. Por merecimiento de pena puede entenderse, de manera general, un juicio global de desvalor del hecho, por concurrir un injusto culpable, especialmente grave. Por su parte, la necesidad de pena se vincularía con el juicio de idoneidad de imponer un castigo a una conducta merecedora de pena, atendiendo a diversas razones como las preventivas, la necesidad y proporcionalidad de la protección jurídico penal, etc. ${ }^{27}$. Desde esta perspectiva, entonces, se ha entendido que el Derecho penal tendría un mayor contacto con el "merecimiento de pena", a diferencia del Derecho procesal penal que estaría fuera de ese ámbito ${ }^{28}$ o se asociaría más a la idea de "necesidad de pena" 29 .

El problema de este enfoque es que sobre las nociones de merecimiento y necesidad de pena hay diversas opiniones. Es una temática de excesiva complejidad donde no existe un total consenso sobre la significación y alcance de los conceptos involucrados ${ }^{30}$. De otro lado, esta ausencia de claridad conceptual dificulta la identificación de estas nociones como fundamento de ciertas instituciones procesales o penales. Por ejemplo, la falta de necesidad de pena puede plasmarse tanto en una norma penal como en una norma procesal penal ${ }^{31}$. El ejercicio del principio de oportunidad en el proceso penal podría ser un buen ejemplo de ello, pues razones de lesividad mínima, por un lado y razones de conveniencia de la persecución, por otro, podrían ser perfectamente concurrentes de manera simultánea.

En otro sentido, hay ciertas situaciones procesales que impiden la aplicación de la pena en donde está ausente tanto el merecimiento como la necesidad de pena ${ }^{32}$.

26 GASCÓN (2004) p. 37, considera que el problema no es la subsunción silogística, sino los problemas que se suscitan en el denominado círculo hermenéutico, en donde "no existen hechos por un lado y leyes por otro, sino un proceso de selección simultánea donde los primeros se reformulan a la luz de las prescripciones jurídicas y donde las segundas se concretan a la luz de la realidad examinada”. En el mismo sentido, STEIN (1990) p. 7: "La prueba de los preceptos jurídicos ha sido inequívocamente separada por el derecho positivo de la prueba de los hechos y de un modo tan enérgico que algunos incluso han negado rotundamente que los preceptos jurídicos sean susceptibles de prueba".

27 Véase, Luzón (1995) pp. 199 ss.

28 BELING (1943) p.5.

29 Kuhlen (2004) p. 149; Frisch (2004) pp. 278 s; NAuKe et al. (2004) p. 114.

30 LuZÓn (1995) p. 199.

31 Roxin (1997) p. 990. Este autor considera que de ello deriva que sea incorrecta la teoría de la "doble naturaleza" de pertenencia de algunas instituciones tanto al Derecho penal como al Derecho procesal.

32 En sentido contrario, LuZÓn (1995) p. 213. 
De la misma forma que el criterio anterior, todas estas dificultades impiden que las nociones de merecimiento de pena y necesidad de pena sean del todo útiles para identificar el campo del Derecho procesal penal y del Derecho penal.

\subsection{El CRITERIO DE LA “FUnCIONALIDAD”}

Finalmente, se ha recurrido a un criterio "funcional" 33 o de efectos prácticos ${ }^{34}$ como elemento diferenciador. Estos criterios, por un lado, operan sobre la base de la construcción de un proceso "ideal" el cual puede ser integrado o no por la institución que analizamos y, por otro, consideran criterios relacionados con la función nomogenética del legislador y sus aspectos vinculados. La pregunta formulada por Kaufmann para distinguir entre Derecho penal material y adjetivo, asociada a este enfoque, es una extrapolación de cuestionamientos similares en sede civil ${ }^{35}$. En efecto, la interrogación era la siguiente: ¿̇tendría que depender la imposición o no imposición de la pena, si fuera posible sin proceso, de esta circunstancia dudosa en cuanto a su naturaleza jurídica, o sería entonces irrelevante esta circunstancia? No obstante la claridad y precisión en la síntesis del problema, esta pregunta es una fórmula cognitiva que trata de eludir el carácter de necesidad del proceso para imponer la pena. Con ello se resta a la norma procesal penal de una de sus características esenciales, y se evita reparar en el nexo que permite al proceso penal tener importancia en los efectos de prevención de la norma penal. De la misma forma, esta posición puede favorecer una mirada unitaria del Derecho procesal (Derecho procesal civil y Derecho procesal penal) en cuanto busca asemejar idealmente ambas áreas procesales a pesar de los innumerables inconvenientes sustanciales.

También se ha intentado afirmar que, no pudiéndose recurrir a un criterio legislativo para fundar la distinción (por cuanto muchas normas procesales se encuentran reguladas en el Código penal y muchas normas penales en el Código de enjuiciamiento penal) ${ }^{36}$, la diferenciación ha de encontrarse en la naturaleza, contenido ${ }^{37}$, sustancia $^{38}$ o finalidad ${ }^{39}$ de las mismas. Se sostiene que la regulación propia de las normas procesales sería la organización de la justicia represiva ${ }^{40}$. Sin embargo, esta visión ha sido rechazada por presentar una noción limitada de la norma procesal penal. Con ello se olvida que no solo se busca que la justicia funcione bien (para lo cual no sería un inconveniente la duración excesiva de los procesos, por ejemplo), sino también la protección de los derechos de los intervinientes

\footnotetext{
33 Antolisei (1988) p. 11; Fenizia (1977) p. 5.

34 Ragués i Vallès (2004) p. 138; Jakobs (2007) p. 411. Por su parte, Roxin (1997) pp. 987 s., atribuye esta pregunta a KAUFMANN, rechazando esta postura por ampliar en demasía el ámbito del Derecho penal material. Véase, Kaufmann (2009) p. 206.

35 Kaufmann (2009) pp. 206 ss.

36 Antolisei (1988) p. 11; Maggiore (1949) p. 34; Gómez Orbaneja (1947) p. 39; Baumann (1973) p. 6.

37 Cavallo (1962) p. 171

38 Maurach y Zipf (1994) p. 198.

39 Gómez Orbaneja (1947) p. 39.

40 Cavallo (1962) p. 171.
} 
(por ello la celeridad es un atributo necesario del proceso penal, atendido a los efectos de “juicio paralelo") ${ }^{41}$.

Sin embargo, este criterio es de difícil apreciación ${ }^{42}$, ya que ello no solo depende de conceptos sustantivos, sino también de las reglas de prueba que se manejen ${ }^{43}$.

Para encontrar una respuesta a la diferenciación de estas dos áreas del ordenamiento jurídico no debe buscarse un único criterio. Muchas veces la realidad muestra matices que se reflejan en ciertos problemas jurídicos, de la misma forma en que podría ocurrir con la distinción entre normas penales y procesales. Sin embargo, tampoco se debe exacerbar el mero etiquetamiento clasificatorio ${ }^{44}$, pues se puede perder la función metodológica de la doctrina jurídica como vehículo de interpretación y comprensión del "dogma" del Derecho positivo.

\section{ASUNCIÓN METODOLÓGICA: "SINCRONISMO" ENTRE DERECHO PENAL Y DERECHO PROCESAL PENAL}

Al margen de si existe o no un criterio que pueda diferenciar completamente las normas de Derecho penal y de las de Derecho procesal penal, lo cierto es que si todos los criterios citados en el apartado anterior generan discrepancias, entonces, ello puede ser un indicio de que, quizás, dicho criterio no exista. Desde otra perspectiva, quizás el tema no debería enfocarse en sus diferencias, sino más bien en cómo influye un área del Derecho sobre la otra. Al respecto realizaré comentarios en lo que sigue de este apartado.

\section{1 ¿SON SUFICIENTES LOS CRITERIOS OFRECIDOS? ¿TIENE IMPORTANCIA, ENTONCES, LA Distinción ENTRE Derecho PENAL y/O NORMA PENAL y Derecho PROCESAL PENAL Y/O NORMA PROCESAL? \\ Como advertía, se atribuyen consecuencias prácticas a la distinción entre Derecho penal y Derecho procesal penal como la aplicación de la máxima "el lugar rige el acto"}

\footnotetext{
41 Lozzi (2004) p. 3. En contra, Battaglini (1949) p. 12; Hassemer y Muñoz Conde (1989) p. 124, consideran que las prescripciones normativas en el proceso penal se deducen de los principios de economía y comunicación. La idea es evitar el trabajo superfluo y facilitar la comprensión escénica.

42 JAKOBS (2007) p. 411, sugiere que los presupuestos tipificados para el aseguramiento de la paz jurídica serían los vinculados con el Derecho procesal penal, sin embargo, también puede verse en la norma penal el factor de resolución de un conflicto, lo cual hace difícil poder aplicar satisfactoriamente este criterio. En este último sentido, Hellmann (2006) p. 2., que considera que el Derecho penal también cumple una función de pacificación social; JESCHECK Y WEIGEND (2002) p. 18., consideran que el Derecho procesal penal sirve a la realización del Derecho penal material, determina la competencia de los órganos de persecución penal y se dirige a la restauración de la paz jurídica perturbada.

43 RAgués I VAllès (2004) p. 144; RoXin (1997) p. 985., considera que la constatación de los presupuestos de procedibilidad está sometida a las reglas de la prueba libre, en cambio la comprobación de las circunstancias de derecho material están sujeto a la valoración de la prueba estricta. En el mismo sentido que Roxin, véase PASTOR (2001) p. 816., agregando que esta circunstancia deviene en la inoperancia del principio in dubio y en la aplicación del régimen de carga de la prueba "civil" a los presupuestos procesales.
}

44 Ragués i Vallès (2004) p. 136. 
(aplicación de ley en el tiempo y espacio) ${ }^{45}$, interpretación y sucesión de leyes ${ }^{46}$, delimitación de competencias legislativas ${ }^{47}$, fundamentación del recurso de casación ${ }^{48}$, entre otras. Estas se habían mantenido en un segundo plano científico hasta que se empezó a dudar de la naturaleza procesal o penal de ciertas instituciones - como la prescripción ${ }^{49}$-, que revivieron la discusión y le dieron más fuerza. Sin embargo -a mi juicio-, todas estas diferencias no revisten ninguna importancia si de aplicarse cualquier estatuto se favorece al reo ${ }^{50}$. El conjunto de normas penales y procesales puede ser entendido como un límite para el ejercicio de la potestad punitiva del Estado, frente al cual el imputado sufre el riesgo de asumir la consecuencia institucional más negativa de todas: la pena privativa de libertad.

Esta visión puede ser una buena alternativa que evidencie la naturaleza de la relación en un sistema de justicia criminal cuyo proceso penal -además de instar a la averiguación de los hechos-, tiene por objeto la protección de los derechos fundamentales de los intervinientes. Desde esta perspectiva, entonces, la protección del individuo imputado es un objetivo que comparten tanto normas penales como procesales. En este sentido, por ejemplo, la existencia de "reglas del juego" sobre el proceso de imposición y aplicación del castigo presentan una finalidad de protección del imputado que se traduce en la justicia de la decisión producida en el marco y cumplimiento de dichas reglas. Con esto no quiero decir que la regulación normativa del sistema de enjuiciamiento no tenga otros fines, o no favorezca a otros intervinientes. Simplemente, que si normas penales y procesales son una restricción para la actuación del Estado y ellas tienen, entre otros fundamentos, la protección y respeto de las libertades fundamentales de las personas (sobre todo del imputado), entonces, no tiene una gran relevancia práctica la formulación de un criterio diferenciador ontológico, porque no lo hay, o no se ha descubierto aún. Lo que sí existe es un conjunto de interpretaciones doctrinales asociadas a la labor de dos áreas que se suponen completamente diferenciadas, pero que, por ocuparse de una función de interpretación dogmática -en sentido amplio no solamente penal-, se hacen partícipe de la misma finalidad de limitación del actuar estatal antes atribuidas a las normas que se interpretan.

Me parece ejemplificador, en este sentido, la opinión de Binder. En efecto, dicho autor considera que si la Política Criminal tuviera un desarrollo metodológico como área de estudio que permitiera analizar la eficacia del programa punitivo y la defensa del derecho

\footnotetext{
45 Frosali (1958) pp. 6; Pagliaro (2000) p. 29; Jescheck y Weigend (2002) p. 18; Maurach y Zipf (1994) p. 32; MeZger (1958) p. 30.

46 Antolisei (1988) p. 11; Fenizia (1977) p. 5; Maggiore (1949) p. 34; Merkel (1906) p. 5; Wessels (1980) p. 14; Prieto-Castro y Gutiérrez de Cabiedes (1989) p. 98. En contra, Jakobs (2007) p. 115: Roxin (1997) pp. 158 y 164 s; STRATENWERTh (2005) p. 72.

47 Ragués i Vallès(2004) p. 135; Gómez Orbaneja (1947) p. 26.

48 Jescheck y Weigend (2002) p. 18; Maurach y Zipf (1994) p. 32. En contra, Gómez Orbaneja (1947) p. 37.

49 En efecto, como señala GÓMEZ (2016) p. 11., la determinación de la naturaleza material o procesal de la prescripción es en absoluto baladí, ya que de ello depende, por ejemplo, la decisiva cuestión de si las normas reguladoras de la prescripción pueden o no ser de aplicación retroactiva in malam partem.

50 Baumann (1973) p. 75., considera que el fin de la prohibición de retroactividad, por ejemplo, es evitar el empeoramiento retroactivo del autor.
} 
de las víctimas, entonces, Derecho penal y Derecho procesal penal solo tendrían por objeto constituir una limitación del actuar del estado ${ }^{51}$.

Por otro lado, se expresa, sin embargo, que la regulación del proceso no podría tener como objetivo el rigor o la benevolencia, sino la certeza ${ }^{52}$. No obstante, la certeza no puede ser entendida como un fin en sí mismo, sino como una garantía para los intervinientes de conocer con antelación las "reglas del juego". Por ello se ha afirmado que el principio de legalidad sustancial traería consigo la exigencia de certeza de la comprobación del supuesto de hecho de modo que "certezza della legge e certeza dell'accertamento sono tutt'uno" ${ }^{3}$. Y como el imputado se puede llevar la peor parte, entonces, será el principal interesado en beneficiarse con esta garantía a fin de prever las consecuencias perjudiciales de un fallo adverso. Es decir, con la certeza del proceso también se beneficia al reo, y un entendimiento adecuado de ella no puede dejar de reconocer que, como garantía, también busca favorecer a los intervinientes, en especial, al imputado.

Por otro lado, la doctrina que destaca el valor diferenciador de la certeza presente en las normas procesales reconoce que cuando estas pueden significar una sanción no es posible aplicar ni la extensión, ni la analogía y deberán ser interpretadas a favor de reo ${ }^{54}$. Este último punto no es baladí si se considera, por ejemplo, que el tiempo de la prisión provisional o preventiva puede ser abonado a una supuesta condena, por lo que la interpretación de esta medida cautelar deberá siempre estar precedida por un criterio de benevolencia y restricción.

El imputado debería ser el primer llamado a obtener algún beneficio "procesal” y de ahí todos los demás intervinientes, pues es el único que se ve expuesto a la mayor consecuencia negativa: la pena. Por ello considero irrelevante jurídicamente determinar con exactitud la naturaleza de la norma que ha llevado a aplicar un beneficio al reo pues -en último término-, el fundamento siempre estará relacionado con la dignidad de la persona del imputado en la aplicación de la potestad punitiva del Estado. La naturaleza material o procesal de la norma no debería desempeñar papel alguno en la seguridad del autor ${ }^{55}$. La distinción entre Derecho penal y Derecho procesal penal no aporta nada al principio de legalidad como garantía ${ }^{56}$. La estrecha cercanía de algunas instituciones procesales con el derecho material obliga a revisar caso a caso la no aplicación de la prohibición de retroactividad penal ${ }^{57}$. De otro lado, en muchas situaciones, funciones adicionales de las normas penales y de las normas procesales penales son equivalentes ${ }^{58}$.

Ante esta inestabilidad en la aplicación de las consecuencias derivada de la distinción entre Derecho procesal penal y Derecho penal, parte de la doctrina penal duda si efectiva-

51 Binder (2007) p. 25.

52 Gómez Orbaneja (1947) p. 26.

53 Pulitanò (2005) p. 954.

54 Gómez Orbaneja (1947) p. 100.

55 Baumann (1973) p. 71.

56 JaKOBS (2007) p. 85.

57 Roxin (1997) pp. 158 y $164 \mathrm{~s}$.

58 Roxin (2000) p. 6, cita como ejemplo las condiciones objetivas de punibilidad y los presupuestos procesales; Peters (1985) p. 11, citando como ejemplo la suspensión de la pena y la "probation". 
mente la delimitación entre ambos sectores del derecho puede tener efectos prácticos totalmente distinguibles ${ }^{59}$.

Para un gran número de normas caracterizadas de "procedimentales" tienen una importancia radical las normas penales ${ }^{60}$. ¿Cómo se puede determinar la "competencia" de los tribunales si no se sabe qué "delito" se ha cometido? ¿Cómo puede hablarse de "hecho punible" o "acción punible" sin referencia alguna al Código penal? ¿Cómo se ha de ponderar la proporcionalidad de la "prisión preventiva o provisional" como medida cautelar si no se sabe el "delito" que se imputa? ${ }^{61}$, etc. Incluso, razones de Derecho penal material pueden incidir en un trámite tan "procesal" como la admisión de la querella ${ }^{62}$.

La estrecha relación entre ambos derechos se viene a confirmar en el momento de dar curso inicial al procedimiento. En el proceso civil se necesita "abrir" el Código Civil solo al dictar la sentencia, al contrario de lo que sucede en el proceso penal. En este último se examina la legislación penal desde el primer momento en que se tiene noticia del caso, como bien lo evidencia Gómez Orbaneja con su concepción de "desarrollo escalonado del proceso" ${ }^{63}$. Desde esta perspectiva, se valora continuamente la antijuridicidad de la conducta, por ejemplo, hasta que se confirma por una sentencia condenatoria o se rechaza con un pronunciamiento absolutorio.

En mi opinión, la visión instrumental de la relación entre ambas parcelas del derecho no es suficiente, por sí sola, para explicar el vínculo ${ }^{64}$. Darle primacía a este criterio provoca una visión de corto alcance de lo que sucede en el proceso penal ${ }^{65}$. Da por supuesto que ambos objetos relacionados son perfectamente distinguibles y delimitados. Sin embargo, el límite es difuso ${ }^{66}$. Por ello se cuestiona, -por ejemplo-, la naturaleza (adjetiva o material) de muchas instituciones como la prescripción ${ }^{67}$, las condiciones objetivas de punibilidad $^{68}$, las normas del concurso real ${ }^{69}$, la facultad de denuncia o querella de la víctima en los delitos privados ${ }^{70}$ e, incluso, de la pena ${ }^{71}$, entre otras ${ }^{72}$. Adicionalmente, se sostiene que existe una zona neutra donde se situarían estos institutos de confluencia de las dos par-

\footnotetext{
59 Ragués i Vallès (2004) p. 133; Roxin (1997) p. 985.

60 Hassemer (2003) p. 72.

61 Gómez Orbaneja (1947) p. 37, considera que los requisitos de la detención, la prisión preventiva, la libertad provisional, el afianzamiento, etc., vienen marcado conjuntamente por normas procesales y sustantivas.

62 Montero (1997) p. 104.

63 Gómez Orbaneja (1947) pp. 36 s.; Hassemer (1984) p. 198; Montero (1997) pp. 101 ss; Siracusano, et al. (1990) p. 12

64 Pagliaro (2000) p. 16; Hassemer (1984) pp. 150 ss.

65 Hassemer (2003) p. 71.

66 Frisch (2004) p. 275; PASTOR (2001) p. 807, considera que presupuestos procesales y demás condiciones que fundamentan o excluyen la punibilidad por fuera del injusto no pueden ser distinguidos satisfactoriamente y, por tanto, Derecho penal y Derecho procesal penal no pueden separarse satisfactoriamente.

${ }_{67}$ Hassemer y Muñoz Conde (1989), p. 122; Jescheck y Weigend (2002) p. 19; Gómez (2016), pp. 9 ss.

68 Pagliaro (2000) p. 27; Wessels (1980) p. 50; Mendes de Carvalho (2005) p. 14.

69 JESCHECK Y WeIGEND (2002) p. 783.

70 OneCa (1986) p. 20.

71 Carnelutti (1943) p. 13.

72 Ragués i Vallès (2004) p. 134.
} 
tes del ordenamiento jurídico ${ }^{73}$, en donde la tendencia predominante de uno u otro no se ha resuelto inequívocamente ${ }^{74}$.

En efecto, la importancia de la norma penal se manifiesta en todo el proceso penal, incluso en aquellas fases en donde se estimaría que no es así, como en el proceso de valoración de la prueba penal. Atendida la importancia de la consecuencia a imponer por el juez, algunos estudios sugieren que la decisión judicial es de carácter bidireccional, a fin de ajustar las premisas (hechos y normas) con la conclusión a imponer ${ }^{75}$. Ello -como ya afirmaba en la introducción de este trabajo-, es sustancialmente distinto a la visión tradicional- a mi modo de ver superada-, del enfoque descriptivo de la decisión judicial como silogismo judicial que sería unidireccional (de las premisas hacia la conclusión), como todavía se sostiene por la doctrina más autorizada en materia probatoria ${ }^{76}$ y en materia de justificación judicial $^{77}$.

Del mismo modo, las concepciones científico sociales del proceso han criticado la visión instrumental ${ }^{78}$. Por otro lado, no solo se discute la distinción en casos determinados, sino también a nivel de principios ${ }^{79}$.

Los aspectos descritos anteriormente muestran que en la aplicación de la distinción analizada no pueda dejar de verse una cierta arbitrariedad ${ }^{80}$ en cuanto se emplean fórmulas vagas, ambiguas y caprichosas ${ }^{81}$. En definitiva, son dos aspectos de la misma realidad ${ }^{82}$, dos cuerpos legales que forman parte del mismo sistema ${ }^{83}$.

No creo que exista un criterio que permita delimitar con precisión las normas penales de las procesales. Si los efectos de esta distinción son los señalados comúnmente por la doctrina (que aquí se reseñaron), entonces, no tiene sentido alguno la diferenciación en cuanto exista la necesidad de interpretar las instituciones sin que se le cause un perjuicio al imputado. Con ello no quiero decir que normas penales y procesales sean idénticas, sino poner en evidencia que sus diferencias son más aparentes de lo que se piensa.

\subsection{Indefinición conceptual de la relación entre Derecho penal y Derecho PROCESAL PENAL: CONSTATACIÓN DEL FENÓMENO DE "CONFIGURACIÓN RECÍPROCA INESTABLE"}

A mi modo de ver, la visión que considera al proceso penal solo como un elemento del sistema de justicia penal que no interactúa con otros es una forma sesgada de intentar

\footnotetext{
73 Manzini (1941) p. 125; Maggiore (1949) p. 35; Peters (1985) p. 11.

74 Roxin (1997) pp. 985 y ss.

75 SimON (2004) p. 522. En el original: "while the strength of supporting variables determines the conclusion, the variables themselves are transformed by the cognitive process so as to provide considerably stronger support for the conclusion".

76 Montero (2008) p. 437; Montero (1997) p. 163; Montero (2012) p. 295.

77 Véase, Chiassoni (1997) pp. 53 ss.

78 Hassemer (1984) p. 150.

79 JaKOBS (2007) p. 411.

80 Ragués i Vallès (2004) p. 133.

81 Pastor (2001) p. 806.

82 Bustos y Hormazábal (1997) p. 106.

83 DrIPPS (2011) p. 410.
} 
construir una imagen del sistema de justicia penal. En efecto, el proceso penal, desde el punto de vista conceptual, sería un espacio de apertura cognitiva y cierre operacional de sistema $^{84}$, cuyos límites jurídicos últimos estarían marcados por el Derecho penal y el Derecho procesal penal (en su parte inferior) y por la Constitución (en su parte superior).

Piénsese, por ejemplo, en el derecho de presunción de inocencia. Este derecho no puede ser analizado satisfactoriamente si no se trae a la vista su naturaleza de derecho fundamental desde el punto de vista del Derecho constitucional. De la misma forma, también puede ser importante para su tratamiento determinar si el mismo se extiende a procedimientos no penales o solo surge cuando se investiga la comisión de un delito. Por último, la naturaleza procesal de este derecho, por ejemplo como regla de tratamiento, puede influir en que la privación de la libertad generada por la medida cautelar de prisión preventiva no sea considerada una pena en sentido estricto, para evitar enjuiciamientos anticipados con anterioridad al Juicio Oral. Sin embargo, la privación de libertad generada por esta institución procesal puede ser abonada a la futura condena, lo que conecta los efectos de esta medida procesal con la aplicación de la consecuencia jurídica de la norma penal. ¿Cómo podría ser satisfactorio realizar un análisis del derecho de presunción de inocencia sin considerar, para su operatividad, la relación que existe entre Derecho Constitucional, Derecho penal y Derecho procesal penal?

Así, por la diversidad de aspectos que tienen importancia en el enjuiciamiento penal este no puede considerarse un sistema jurídico interno cerrado ${ }^{85}$. Las normas penales exigirán para su aplicación no solo un sistema dogmático penal acabado, sino también el cumplimiento de elementos e instituciones procesales penales que harán las veces de condicionantes para la aplicación de la pena ${ }^{86}$. Y, en este sentido, el proceso penal aparece como parte del contexto aplicativo de las normas penales, necesario para su operatividad ${ }^{87}$. No debe olvidarse, en este sentido que no hay pena sin un proceso penal previo ${ }^{88}$.

De la misma forma, el efecto de la prevención de la norma penal se complementa con las exigencias del proceso penal, pues, si estas últimas no se cumplen, se pone en riesgo la amenaza de la imposición del castigo ${ }^{89}$. Esta retroalimentación conlleva la exigencia de que el proceso penal pueda ser una herramienta eficaz de comprobación del delito y de imposición de consecuencias delictivas ${ }^{90}$.

Piénsese, por ejemplo, en lo que ha sucedido en España luego de la dictación de la Ley Orgánica 5/2010, de 22 de junio, que estableció la Responsabilidad penal de las personas jurídicas. En su aplicación se evidenció claramente un déficit de las normas de en-

\footnotetext{
84 Vera (2015) p. 10.

85 Hassemer (2003) p. 69; Vera (2015) p. 10.

86 En este sentido, Roxin (2000) p. 3.

87 Friedman (1975) p. 16.

88 Armenta (2013), p. 27.

89 En este sentido, LEONE (1974) p. 299, sostiene que "non è tanto la previsione della pena per taluni fatti che mira a dissuadere dal delitto quanto l'effettiva messa in moto del meccanismo processuale nel caso di sopposta violazione della norma penale; la pronuncia della condanna si pone quindi come la più efficace attuazione della funzione di prevenzione generale."

90 Pulitanò (2005) p. 958.
} 
juiciamiento penal lo que ha llevado a la dictación de una serie de modificaciones que han tenido por objeto adecuar el proceso penal al juzgamiento de las personas jurídicas ${ }^{91}$. De lo contrario, la validez y eficacia del castigo de las personas jurídicas podría haberse puesto en duda.

Considerando lo anterior, la estructuración del proceso penal es un "continente receptivo" donde confluyen elementos del Derecho penal, del Derecho procesal clásico ${ }^{92}$ y del Derecho constitucional en cuanto fundamento y límite del ejercicio de la potestad punitiva del Estado ${ }^{93}$. Todo ello hace perder utilidad a la delimitación irrestricta entre todas estas áreas del derecho confluyentes en el proceso penal, como asimismo a la búsqueda de un criterio correcto y satisfactorio que permita distinguir entre normas penales y procesales. Con ello no estoy afirmando que no sea importante para el proceso judicial distinguir si se aplica una norma penal o una norma procesal ${ }^{94}$. Lo que afirmo es que la búsqueda de un criterio universalista es estéril, pues la decisión judicial es el resultado de la aplicación indistinta de la conjunción entre normas penales, procesales penales y constitucionales, cuya interpretación condiciona e influye en todo el conjunto y en sus elementos particulares. Piénsese, por ejemplo, que la gravedad y éxito de la acusación por un delito grave se condiciona a la existencia de prueba de cargo que, a su vez, sea lícita. Sin ello, aunque la acusación sea técnicamente acabada desde el punto de vista del Derecho penal, la norma penal queda sin aplicación.

En definitiva, la relación entre Derecho penal y Derecho procesal penal es ondulante, inestable, dinámica ${ }^{95}$, influida por el pasado, el presente y el futuro. A este respecto solo es posible cognitivamente trazar ciertas líneas de tendencias ${ }^{96}$ entre un área y otra, pero bajo ningún punto encontrar criterios descriptivos que expliquen a cabalidad la diferenciación.

Como anotaba, Derecho penal y Derecho procesal penal, en cuanto subsistemas del gran sistema de justicia penal se influencian recíprocamente, sin que ello signifique afirmar que se trata de normas jurídicas de idéntica naturaleza. Sin embargo, la influencia de uno sobre el otro puede ser percibida como una impropiedad científica. Por ejemplo, el nacimiento del derecho procesal -y, por extensión, de todas las áreas que buscan cierta autonomía dentro del Derecho- está fuertemente influenciada por el positivismo filosófico que asociaba a cada ciencia como tal un objeto y método de estudio propio. En la evolución del Derecho procesal ello se plasmaría en la incesante búsqueda histórica de una diferenciación respecto del Derecho material ${ }^{97}$.

\footnotetext{
91 Por ejemplo, Ley 37/2011, de 10 de octubre "de medidas de agilización procesal" o la LO 13 /2015, de 5 de octubre, de "modificación de la Ley de Enjuiciamiento Criminal para el fortalecimiento de las garantías procesales y la regulación de las medidas de investigación tecnológica”. Al respeto, véase, VerA (2016). p. 201 ss.

92 Gómez Orbaneja (1947) p. XVII; Armenta (1995) p 450.

93 Hassemer y Muñoz Conde (1989) p. 124.

94 Gómez Orbaneja (1947) p. XVIII.

95 Leone (1988) p. 31; Vera (2015) p.12.

96 En contra, Díaz Cantón (2005) p. 27.

97 Alcalá-Zamora (1992) p. 309.
} 
La importancia de la estrecha relación entre Derecho penal y procesal penal para el funcionamiento del sistema de justicia penal es algo que se advertía implícitamente, al señalar que ambas áreas del Derecho debieran exhibir una misma actitud fundamental ${ }^{98}$ o sintonía paralela99. Los ciudadanos que toman contacto con el sistema de justicia penal deben recibir un mensaje coherente, ya sea provenga de la aplicación de la norma penal, ya sea provenga de la aplicación de la norma procesal penal. Por ejemplo, un proceso penal que no cautele garantías puede transformar al Código penal en un derecho de policía ${ }^{100}$. En otro sentido, el principio de legalidad se proyecta sobre el fin "represivo" del Derecho penal y sobre la finalidad "garantista" del proceso penal ${ }^{101}$, pero los ciudadanos lo sienten como "uno" solo, por lo que debería ser un aspecto de mutua incumbencia ${ }^{102}$.

De esta manera se muestra inútil o superficial ${ }^{103}$ cualquier distinción irrestricta para estos efectos ${ }^{104}$.

A mi modo de ver, Derecho penal y Derecho procesal penal presentan efectos de alcance recíproco ${ }^{105}$, de forma tal que se condicionan mutuamente respecto a su fuerza ${ }^{106}$. Por un lado el Derecho penal determina la naturaleza del delito como acto humano productor de efectos jurídicos ${ }^{107}$, por otro, las normas procesales penales son una condición necesaria de la imposición de la pena ${ }^{108}$ que, a su vez, no solo es una consecuencia jurídica de la norma penal, sino también un efecto del proceso ${ }^{109}$.

Todo lo anterior nos lleva a afirmar que la visión que mejor refleja la relación entre Derecho penal y Derecho procesal penal, como parte del sistema de justicia penal, es aquella de carácter sincrónico o retroalimentación entre normas penales y procesales. De esta

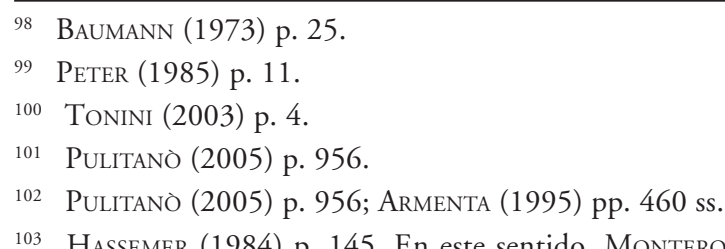

103 Hassemer (1984) p. 145. En este sentido, Montero (1997) p.111; Hellmann (2006) p. 1, afirma que el objeto del Derecho procesal penal no es claro; Roxin (2000) p. 4, plantea que el fin del proceso penal tiene una naturaleza compleja. Siracusano, et al. (1990) pp. 17 ss, considera que para comprender la autonomía de la actividad procedimental jurisdiccional penal es necesario olvidar la distinción entre norma de organización (estática) y de conducta (dinámica), para considerar que la convergencia de las denominadas normas de organización con otras normas procesales pueden producir un efecto jurídico preciso.

104 En este sentido, véase Garafoli (2006) p. 2.

105 Frisch (2004) p. 531; Pulitanò (2005) pp. 970 s; Peters (1963) p. 11; Peters (1985) p. 10.

106 En este sentido, Peters (1963) p. 10, considera que "das materielle Strafrecht hat als solches keine unmittelbare Wirkkraft. Es kommt erst in der Rechtspflege zur Geltung". También este autor señala "das Strafrecht wird im Strafproze in doppelter Weise in die Wirklichkeit umgesetzt. Einmal gilt der Satz: "Ohne Proze keine Anwendung des Strafrechts", sodann: "Im Strafproze findet das Strafrechts erst seine nähere rechtliche Ausgestaltung»". En el mismo sentido, Peters (1985) p. 11, considera que el Derecho procesal penal tiene una fuerza configurada por el Derecho penal material. En el original: "Das Strafproze recht hat eine das materielle Strafrecht gestaltende Kraft".

107 Gómez Orbaneja (1947) pp. 28 y 34.

108 Ragués i Vallès (2004) p. 138; CaRnelutti (2007) p. 59; CaRnelutti (1943) p. 12, sostiene "non il reato è un presupposto del processo ma il processo è una condizione del reato.... insomma tutto il diritto penale è diritto processuale"; Baumann (1973) p. 49; Hassemer (1984) p. 150; Gómez Orbaneja (1947) p. 34; Díaz Cantón (2005) p. 2.

109 Gómez Orbaneja (1947) p. 27. 
forma se conseguirá esa misma "actitud fundamental" y esa visión coherente que precisa el ciudadano expuesto a la aplicación de una pena por medio del proceso penal. La misma sincronía permite explicar por qué para ciertos efectos la distinción pareciere irrelevante, como cuando se trata de protección de garantías, ya sea provenga del Derecho penal, ya sea provenga del Derecho procesal penal, pues la ineficacia de la protección cuestionará la legitimidad del sistema de justicia penal en su conjunto, independiente si el déficit proviene de un área o de otra ${ }^{110}$. Pero por otro lado, también esta sincronía explica por qué para el sistema de justicia penal es importante que normas procesales, por ejemplo, participen de funciones normalmente atribuidas a las normas penales, como cuando se afirma que el proceso penal también puede ser una variable político criminal ${ }^{111} \mathrm{o}$, derechamente, una condición necesaria de la imposición de la pena que a veces algunos asimilan a una condición objetiva de punibilidad ${ }^{112}$.

La consecuencia práctica de ello es que, sobre la base de este sincronismo, se puedan interpretar las normas procesales penales conforme a cánones tradicionales y garantistas atribuidos a la interpretación de normas penales. Siguiendo con el ejemplo de la prisión preventiva como medida cautelar o instituto procesal, ¿por qué debiera aplicarse la ley vigente que rige el acto en vez de una posible retroactividad favorable a reo cuando la privación de libertad preventiva repercute en la determinación del tiempo de prisión efectiva obligada por la norma penal en el caso de sentencia condenatoria? Si se trata de la determinación del quantum de la pena de la norma penal podemos hacer una interpretación retroactiva o favorable a reo, pero si se trata de los requisitos de la prisión preventiva, entonces solo debe ser aplicable la ley vigente al momento de la dictación del acto procesal o la vigente a la "hora del proceso"113. ¿Por qué? ¿Acaso resulta prescindible proteger las garantías del ciudadano expuesto al enjuiciamiento con independencia de la fuente jurídica formal de su afectación? ${ }^{114}$. Por lo demás una aplicación retroactiva en favor de reo puede oponerse al criterio imperante de interpretación restrictiva de las medidas cautelares, precisamente, por ampliar el ámbito del supuesto fáctico incluido bajo la vigencia temporal de la norma ${ }^{115}$. Al respecto, y para cerrar el punto, traigo a colación las palabras de Hassemer: “(...) por qué los procesos de control social que son más bien de carácter informal tienen que regirse por determinadas reglas procedimentales que son el colmo de

\footnotetext{
110 Bustos y Hormazábal (1997) p. 77.

111 Vera (2015) p. 10

112 PASTOR (2001) p. 807; CorCoy (2012) p.172.

113 Oliva y Fernández (1993), p. 256: "Así pues, la común irretroactividad general de las leyes sustantivas y de las procesales se refleja en una forma de aplicación distinta a la hora del proceso: la ley sustantiva aplicable en él puede estar derogada; la procesal, en cambio, siempre ha de estar vigente: esto es así porque esa "hora del proceso", que es, obviamente, la que cuenta para la aplicación de la ley procesal, es diferente de la hora de la relación o situación jurídica o del derecho o deber que constituye la res in iudicio deducta". En este sentido, el CPP contiene una norma referida a la aplicación temporal de la ley procesal (artículo 11), pero ella solo permite la aplicación ultractiva a favor de reo, quedando el cuestionamiento abierto en materia de retroactividad.

114 En favor de la retroactividad de leyes procesales que beneficien a reo, véase, FAIRÉN (1992), p. 67.

115 A este respecto, el Código procesal penal chileno en su artículo 5, inciso final señala: "Las disposiciones de este Código que autorizan la restricción de la libertad o de otros derechos del imputado o del ejercicio de alguna de sus facultades serán interpretadas restrictivamente y no se podrán aplicar por analogia".
} 
la formalización"116. Lo anterior sugiere plantearse lo siguiente: ¿por qué el carácter formal de una norma procesal debiera condicionar sus efectos e interpretación si se le considera un elemento más del sistema de justicia penal?

Sé que el tema es complejo y que no es posible agotarlo en este trabajo -ni tampoco mi pretensión final-, pero me basta con poner de relevancia la relación sincrónica de las normas procesales con las normas penales y todas sus consecuencias que he enunciado.

Una mirada independiente, autónoma, autosuficiente y unilateral del análisis del proceso penal no es satisfactoria como un pretendido instrumento de justicia en un Estado social y democrático de derecho ${ }^{117}$. El proceso penal, en sí mismo, es una incesante búsqueda de equilibrios entre los derechos y prerrogativas de los intervinientes ${ }^{118}$ que no puede estar ajena al contacto de los mismos con normas penales y constitucionales y que se presenta como la principal fuente de dificultades, pero también como atractivo del derecho procesal penal moderno ${ }^{119}$. El Derecho procesal penal no solo está al servicio del Derecho penal, sino también del derecho de defensa y de libertad de los ciudadanos ${ }^{120}$, y otorga a la norma penal su principal contacto con la realidad social. Así, cada vez es más incuestionable la influencia y vinculación recíproca entre Derecho y la sociedad, demostrada, también, a partir de la relación entre Derecho penal y Derecho procesal penal ${ }^{121}$.

Esto último debería llevar a evaluar si es acertado el método de enseñanza utilizado en las universidades. En este sentido, una relación sincrónica o de retroalimentación entre normas penales y procesales se corresponde mejor con modelos de enseñanza universitaria donde el currículo de Derecho penal conviviera con el de Derecho procesal penal -y, por extensión, con el de Derecho probatorio-, situación que no es la normalidad en universidades españolas y chilenas, por el contrario de lo que sucede parcialmente en Alemania.

Por su parte, también ponderar si es conveniente que la doctrina procesal penal siga manteniendo, de manera casi indubitada, el punto de referencia del proceso civil, a fin de dar más importancia en sus estudios a la norma penal a aplicar ${ }^{122}$. En este sentido, no es ajeno al mundo del derecho procesal encontrar posiciones que fundamentan una unidad de proceso entre proceso penal y proceso civil ${ }^{123}$. Sin embargo, aunque pueden haber elemen-

\footnotetext{
116 Hassemer (2016) p. 42.

117 Hellmann (2006) p. 7.

118 Cfr. Baumann (1973) p. 16, quien considera que "en cada grado del procedimiento los derechos y deberes de los sujetos procesales deben hallarse dentro de una relación equilibrada”.

119 Roxin (2000) p. 4.

120 Pulitanò (2005) p. 968. En el original: “Ë, il proceso penale, un servo gentiluomo di più padroni: non solo del diritto penale, ma anche dei diritti di difesa che costituisco un quid proprium della dimensione processuale, e di diritti di libertà radicati a livello costituzionale, che all'ottica penalistica pongono limiti invalicabili”.

121 En este sentido, Dripps (2011) p. 410: "The law in action can modify, even nullify, the law on the books. The substance-procedure relationship, then, is both fundamental and problematic in the positive law and academic literature on criminal justice".

122 Ragués i Vallès (2004) p. 163.

123 Así, por ejemplo, en Chile, Вотто (2008) p. 560: "En esta discusión histórica, aún sin superar, tomo partido absoluto por la teoría unitaria, ya que me parece evidente que no existen dos procesos, uno civil y otro penal". Una tesis ecléctica puede encontrase en Armenta (2013) pp. 28 y 29.
} 
tos comunes, lo cierto es que la esencia de lo discutido en uno u otro proceso es totalmente distinto, a un punto tal que se modifica su naturaleza: en el proceso civil es prevalente la discusión de intereses privados; en el proceso penal, por su parte, la esencia radica en un interés público prevalente en la realización de la potestad punitiva del Estado. Piénsese lo importante de ello para aplicar o no las normas de la carga de la prueba civil al proceso penal. Y, admitiendo ello, lo incongruente que puede ser aplicar a la legítima defensa, por ejemplo, el régimen de carga de la prueba "civil" de los hechos impeditivos o excluyentes cuando se trae a la vista el principio de objetividad que rige la actuación de investigación del Ministerio Público. En este sentido, es mayoritario el parecer en nuestros tribunales en el caso de eximentes de responsabilidad, como la legítima defensa, que se debe utilizar el concepto de carga de la prueba y que la prueba de estas corresponde a quien la invoca ${ }^{124}$. En otro sentido, asumiendo correcta la utilización del concepto de carga de la prueba, tampoco aparece del todo claro, especialmente en el caso de la legítima defensa, que la relación de esta con el hecho imputado sea equivalente a la relación hecho constitutivo/hecho impeditivo o excluyente de la teoría de la carga de la prueba civil. Piénsese que en materia penal el injusto -sobre el cual influye una causal de justificación como la legítima defensa- no presenta una división clara y prístina con la tipicidad penal, pues las causales de justificación pueden ser consideradas elementos complementarios, en el caso concreto, de la ilicitud contenida en la conducta típica que se prohíbe ${ }^{125}$.

Esta relación sincrónica entre Derecho penal y Derecho procesal penal es un llamado a superar las rígidas fronteras entre ambas disciplinas ${ }^{126}$, mostrando una actitud de apertura, sin que ello signifique necesariamente un desconocimiento de ciertas parcelas de autonomía del Derecho procesal penal como disciplina ${ }^{127}$, o una renuncia a una diferenciación conceptual en el plano metodológico del Derecho penal. Simplemente "la lucha de escuelas" no debe olvidar que, finalmente, en el banquillo de los acusados hay un ciudadano con el atributo de dignidad humana, que puede verse afectado por diferencias conceptuales o técnicas a la hora de aplicar las normas de Derecho penal o de Derecho procesal penal al interior del sistema de justicia penal.

\section{CONCLUSIÓN}

La visión que explica la relación entre normas penales y procesales como meramente instrumental es una opinión de corto alcance que no logra reflejar gran parte de las funcio-

\footnotetext{
124 Por ejemplo, Sentencia de Tribunal del Juicio Oral en lo Penal de Antofagasta de fecha 23 de julio de 2008, Rit 113-2008; Sentencia de Tribunal del Juicio Oral en lo penal de San Antonio, de fecha 28 de marzo de 2007, Rit 12-2007; Sentencia del Tribunal del Juicio Oral en lo Penal de Concepción, de fecha 7 de septiembre de 2008, Rit 290-2008, entre otras.

125 Sobre la relación de la tipicidad y la antijuridicidad penal véase, Mir PuIG (2011) pp. 154 ss.

126 Ragués i Vallès (2004) p. 162; Pulitanò (2005) pp. 952 ss., considera que "Diritto penale sostanziale e proceso penale fanno parte di un'istituzione unitaria, nella quale il volto garantista e il volto repressivo sono comprensenti, entrambi agganciati al pricipio di legalità, e vanno alla ricerca di ragionevoli equilibri”.

127 En este sentido, Pulitanò (2005) pp. 960 ss.
} 
nalidades que tiene el proceso penal moderno más allá de la mera realización de la norma penal.

Por otro lado, los criterios que fundan una diferenciación entre normas penales y procesales sobre la base de la aplicación judicial de las mismas, de la pertenencia al complejo del hecho penado, del merecimiento y necesidad de pena, o de la funcionalidad de normas penales y procesales no son enteramente satisfactorios si se considera el amplio abanico de funcionalidades de las normas procesales penales, por un lado, y la estrecha vinculación con las normas penales, por otro.

Así, una diferenciación entre normas procesales y penales sobre la base de los criterios anotados, además de imprecisa, pudiera servir de instrumento para un mero etiquetamiento clasificatorio arbitrario, sobre la base de cual atribuir efectos a la interpretación de las normas procesales penales que pueden ser perjudiciales para el reo.

Una visión global o de conjunto del proceso penal respecto al sistema de justicia penal nos permitirá entender de mejor forma la operatividad del mismo. Por otro lado, la asunción de una configuración sincrónica o de retroalimentación entre Derecho penal y Derecho procesal penal, lejos de perjudicar la autonomía, genera una visión más realista de lo que sucede en los tribunales. De esta forma, el destierro de las rígidas barreras metodológicas entre norma penal y norma procesal permitirá a esta última cumplir de mejor forma la función de garantía o tutela de los derechos fundamentales de los intervinientes. Por último, a través de las indicaciones que he realizado en este trabajo se puede empezar a discutir sobre la pertinencia de una metodología del Derecho procesal penal que considere o se halle en la misma sintonía con los principios más importantes del Derecho penal. De ahí que afirmara la necesaria existencia de un sincronismo o retroalimentación entre las normas del Derecho penal y del Derecho procesal penal.

\section{BIBLIOGRAFÍA CITADA}

Alcalá-Zamora, Niceto (1992): Estudios de teoría general e historia del proceso (D.F. Universidad Nacional Autónoma de México).

AleXY, Robert (2007): Teoría de la argumentación jurídica (trad. Manuel Atienza e Isabel Espejo, Madrid, Centro de Estudios Políticos Constitucionales, segunda edición).

Antolisei, Francesco (1988): Manual de Derecho penal. Parte general (trad. de Jorge Guerrero y Marino Ayerra Redín, Bogotá, Temis, octava edición).

Armenta Deu, Teresa (2013) Lecciones de Derecho procesal penal. (Madrid, Marcial Pons, séptima edición).

Armenta Deu, Teresa (1995): "Pena y proceso: fines comunes y fines específicos", Anuario de Derecho penal y Ciencias penales, Tomo 48, Fasc/Mes 2: pp. 441-464.

Asencio Mellado, José María (2010): Derecho procesal penal (Valencia, Tirant lo Blanch, quinta edición).

Asencio Mellado, José María (1991): Principio acusatorio y derecho de defensa en el proceso penal (Madrid, Trivium).

Atienza, Manuel (2003): El sentido del derecho (Barcelona, Ariel, segunda edición).

Baumann, Jürgen (1973): Derecho penal (trad. Conrado Finzi, Buenos Aires, Depalma). 
Bacigalupo, Enrique (1999): Derecho penal. Parte General (Buenos Aires, Hammurabi, segunda edición).

Battaglini, Giulio (1949): Diritto penale. Parte generale (Padova, Cedam, terza edizione)

Beling, Ernst (1943): Derecho procesal penal (trad. Miguel Fenech. Barcelona, Madrid, Buenos Aires, Río de Janeiro, Labor).

Binder, Julio (2001):" ¿Es posible todavía la realización del proceso penal en el marco de una Estado de Derecho?", en Lascano, Carlos (dir.) Nueva formulaciones en las ciencias penales: homenaje a Claus Roxin (Lerner. Córdoba) pp. 791-804.

Binder, Julio (2007): Tensiones político-criminales en el proceso penal, Revista Jueces para la Democracia, No 60: pp.21-36.

Botto, Hugo (2008), "Distinción entre proceso y procedimiento", en Rodríguez Collao (coord.) Delito, pena y proceso (Santiago, Editorial Jurídica de Chile) pp 553-562.

Bustos Ramírez, Juan/Hormazábal Malarée, Hernán (1997): Lecciones de Derecho penal (Madrid, Trotta).

Carnelutti, Francesco (1943): Lezioni di Diritto penale (Milano, Giuffrè).

Carnelutti, Francesco (2007): Teoría general del delito (trad. de W. Roces, Madrid, Reus)

Cavallo, Vincenzo (1962): Diritto penale. Parte generale (Napoli, Editrice Dott. Eugenio Jovene, seconda edizione).

Corcoy Bidasolo, Mirentxu (2012): Crisis de las garantías constitucionales a partir de las reformas penales, en Mir Puig, Santiago/Corcoy Bidasolo, Mirentxu, Constitucion y sistema penal (Barcelona, Marcial Pons) pp. 153-174.

Córdoba Roda, Juan (1974): “Consideraciones sobre la jurisprudencia penal”, Revista Jurídica de Cataluña. Vol.73. no1: pp 119-132.

Chiassoni, Pierluigi (1997): "Notas para un análisis silogístico del discurso judicial", Doxa, no 20: pp. 53-90.

Díaz Cantón, Fernando (2005): "Vicisitudes de la cuestión de la autonomía o dependencia entre el Derecho penal y el Derecho procesal penal", Revista general de Derecho procesal. No 7.

DrIPPS, Donald (2011): “The Substance-Procedure relationship in Criminal Law”, en R.A. Duff/Green, Stuart (eds.) Philosophical Foundations of Criminal Law (Oxford, Oxford University Press) pp. 409-432.

FAIREN, Víctor (1992): Teoría general del derecho procesal (México, Universidad Nacional Autónoma de México).

FenIZIA, Guiseppe (1977): Diritto e procedura penale criminología e legislazione minorile (Padova, Cedam).

Feuerbach, Paul Johann Anselm Ritter (1989): Tratado de Derecho penal (trad. Eugenio Zaffaronni e Irma Hagemeier, Buenos Aires, Hammurabi).

Freund, Georg (2004): "Sobre la función legitimadora de la idea del fin en el sistema integral del Derecho penal”, en Wolter, Jürgen/Freund, Georg (eds): El sistema integral del derecho penal (Barcelona, Marcial Pons) pp. 91-128.

Friedman, Lawrence (1975): The legal system. Russel Sage Foundation. New York, 1975.

Frisch, Wolfgang (2004): "Delito y sistema del delito", en Wolter, Jürgen/Freund, Georg (eds): El sistema integral del derecho penal (Barcelona, Marcial Pons) pp. 193-280. 
Gascón Abellán, Marina (2004): Los hechos en el Derecho (Barcelona, Marcial Pons, segunda edición).

GARAFOLI, Vincenzo (2006): Istituzioni di diritto processuale penale (Milano, Giuffrè Editore, seconda edizione).

García Pablos, Antonio (2005): Introducción al Derecho penal (Madrid, Ed. Universitaria Ramón Areces).

Gómez Colomer, Juan-Luis (1997): El proceso penal español (Valencia, Tirant lo Blanch, segunda edición).

Gómez Martín, Víctor (2016): La prescripción del delito (Montevideo, Buenos Aires, B de $\mathrm{F})$.

Gómez Orbaneja, Emilio (1947): Comentarios a la Ley de Enjuiciamiento Criminal, Tomo I (Barcelona, Bosch).

Hassemer, Winfred (1984): Fundamentos del derecho penal (trad. Francisco Muñoz Conde, Barcelona, Bosch).

Hassemer, Winfred (2003): Critica al derecho penal de hoy (Buenos Aires, Ad-Hoc, segunda edición).

Hassemer, Winfred (2016) ¿Por qué castigar? (trad. Manual Cancio y Francisco Muñoz, Valencia, Tirant lo Blanch).

Hassemer Winfried/Muñoz Conde Francisco (1989): Introducción a la criminología y al derecho penal (Valencia, Titant lo Blanch).

Hellmann, Uwe (2006): Strafprozessrecht (Berlin-Heidelberg, Springen, zweite Auflage).

Jakobs, Günther (2007): Derecho penal. Parte general (trad. Joaquín Cuello Contreras y José Luis Serrano González de Murillo, Madrid, Marcial Pons, segunda edición).

Jescheck, Hans-Heinrich/Weigend Thomas (2002): Tratado de Derecho penal. Parte general (trad. Miguel Olmedo, Granada, Comares, quinta edición).

JiméneZ De AsúA, Luis (1964): Tratado de derecho penal, Tomo I (Buenos Aires, Ed. Losada)

Kelsen, Hans/Klug, Ulrich (1988): Normas jurídicas y análisis lógico (trad. Juan Carlos Gardella, Madrid, Centro de Estudios Constitucionales).

Kaufmann, Hilde (2009): Pretensión penal y derecho a la acción penal (trad. Guido Müller y Félix Pedreira, Madrid, Editorial Ramón Areces).

Kuhlen, Lothar (2004): “¿Es posible limitar el Derecho penal por medio de un concepto material del delito?, en Wolter, Jürgen/Freund, Georg (eds): El sistema integral del derecho penal (Barcelona, Marcial Pons) pp. 129-152.

Larez, Karl (1994): Metodología de la ciencia del derecho (trad. Marcelino Rodríguez Molinero, Barcelona, Ariel).

Larroucau, Jorge (2012), "Hacia un estándar de prueba civil”, Revista Chilena de Derecho, No3, vol.39: pp.783-808.

Leone, Giovanni (1988): Manuale di Diritto processuale penale (Milano, Jovene, tredicesima edizione).

LEONE, Mauro (1974): Il tempo nel diritto penale sostantivo e processuale (Napoli, Jovene).

LesCH, Heiko Hartmut (2001): Strafprozessrecht (Luchterhand, Neuwied, zweite Auflage).

LONGHI, Silvio (1911): Repressione e prevenzione nel diritto penale attuale (Milano, Libraria). 
LozzI, Gilberto (2004): Lezioni di Procedura penale (Torino, Giappichelli Editore, sesta edizione).

Maggiore, Guiseppe (1949): Diritto penale. Parte generale. Tomo I (Bologna, Zanichelli Editore, quinta edizione).

Manzini, Vicenzo (1941): Tratado de Derecho penal. Tomos I, III (trad. Santiago Santis Melendo, Buenos Aires, Ediar editores).

Maurach, Reinhart/ Zipf, Heinz (1994): Derecho penal. Parte general (trad. Jorge Bofill Genzsch y Enrique Aimone Gibson, Buenos Aires, Astrea).

MAZZARESE, Tecla (1996): "Lógica borrosa y decisiones judiciales: el peligro de una falacia racionalista", Doxa, 19. trad. cast de José Juan Moreso: pp. 201-228.

Mendes de Carvalho, Erika (2005): "Las condiciones de procedibilidad y su ubicación sistemática”, Revista electrónica de Ciencia penal y Criminología, No7: pp. 1-28.

Merkel, Adolf (1906): Derecho penal, Tomo I (trad. P. Dorado, Madrid, La España moderna).

Mezger, Edmund (1935): Tratado de derecho penal, Tomo I (Madrid, Editorial Revista de Derecho privado).

Mezger, Edmund (1958): Libro de Estudio. Parte General (Trad. Conrado Finzi y Ricardo Núñez, Buenos Aires, Editorial Bibliográfica argentina).

Mir Puig, Santiago (2003): Introducción a las bases del derecho penal (Montevideo-Bs. Aires $\mathrm{B}$ de $\mathrm{F}$, segunda edición).

Mir Puig, Santiago (2011): Derecho penal. Parte general (Barcelona, Reppertor, novena edición).

Mir Puig, Santiago/Luzón Peña, Diego-Manuel (coords.)(1995): Causas de justificación y de atipicidad en el Derecho penal (Pamplona, Aranzadi).

Montero Aroca, Juan (2008): Proceso penal y libertad (Navarra, Aranzadi).

Montero Aroca, Juan (2012): Derecho jurisdiccional III (Valencia, Tirant lo Blanch, vigésima edición).

Montero Aroca, Juan (1997): Principios del proceso penal (Valencia,Tirant lo Blanch).

Morillas Cuevas, Lorenzo (1990): Metodología y ciencia penal (Granada, Universidad de Granada).

Muñoz Conde, Francisco/García Arán, Mercedes (2010): Derecho penal. Parte general (Valencia, Tirant lo Blanch, octava edición).

Nauke, Wolfgang/ Hassemer, Winfred/Lüderssen, Klaus (2004): Principales problemas de la prevención general (Montevideo/ Bs. Aires, B de F).

Octavio de Toledo y Ubieto, Emilio/ Huerta Tocildo, Susana (1986): Derecho penal. Parte General (Madrid, Rafael Castellanos, segunda edición).

OneCA, Antón (1986): Derecho penal (Madrid, Akal, segunda edición).

De la oliva, Andrés /Fernández, Miguel (1993): Derecho procesal civil. Tomo I. (Madrid, Centro de Estudios Ramón Areces).

Ortiz de Urbina Gimeno, Íñigo (2007): La excusa del positivismo (Navarra, Aranzadi).

Pagliaro, Antonio (2000): Principi di diritto penale. Parte generale (Milano, Giuffrè, Settima edizione). 
PASTOR, Daniel (2001): "Acerca de presupuestos e impedimentos procesales y sus tendencias actuales”, en LASCANO, Carlos (dir.) Nuevas formulaciones en las ciencias penales: homenaje a Claus Roxin (Córdoba, Lerner) pp. 169-196.

Peters, Karl (1963): Die strafrechtsgestaltende Kraft des Strafprozesses (Tübingen, J.C.B Mohr).

Peters, Karl (1985): Strafproze (Heildelberg, C.F. Müller Juristischer Verlag, vierte Auflage).

Pulitanò, Domenico (2005): "Sui rapporti fra Diritto penale sostanziale e processo", Rivista italiana di diritto e procedura penale, no 43, fasc 3: pp. 951-973.

Prieto-Castro, Leonardo/Gutiérrez de Cabiedes, Eduardo (1989): Derecho procesal penal (Madrid, Tecnos, cuarta edición).

Quintero Olivares, Gonzalo/Morales Prats, Fermín (2010): Parte General del Derecho penal (Navarra, Aranzadi, cuarta edición).

RAGUÉS I VALlĖs, Ramon (2004): "Derecho penal sustantivo y Derecho procesal penal: Hacia una visión integradora”, La reforma del proceso penal peruano, Anuario de Derecho penal peruano 2004: pp. 129- 163.

Ramos Méndez, Francisco (2010): Enjuiciamiento criminal: novena lectura constitucional (Barcelona, Atelier).

Roxin, Claus (1997): Derecho penal. Parte General. Tomo I (trad. Diego Luzón Peña, Miguel Díaz y Javier de Vicente Remesal, Madrid, Civitas).

Roxin, Claus (2000): Derecho procesal penal (trad. Gabriela Córdoba y Daniel Pastor, Buenos Aires, Editorial del Puerto).

SÁnchez de la Torre, Ángel (1965): Curso de Sociología del Derecho (Madrid, Editorial Revista de Derecho privado).

SCHAuER, Frederick (1988): "Formalism", The Yale Law Journal, Vol.97, No 4: pp. 509-548.

Silva Sánchez, Jesús María (1992): Aproximaciones al Derecho penal contemporáneo (Barcelona, Bosch).

Simon, Dan (2004): "A third view of the black box: Cognitive Coherence in legal decision making”, University Chicago Law Review, No 71: pp. 511 ss.

Siracusano, Delfino/Dalia, Andrea/Galati, Antonino/Tranchina,Giovanni/Zappalà, Enzo (1990): Manuale di diritto Processuale Penale. Volumen I (Milano, Giuffrè Editore).

STEIN, Friedrich (1990): El conocimiento privado del juez (trad. Andrés de Oliva, Madrid, Centro de Estudios Ramón Areces).

Stratenwerth, Günter (2005): Derecho penal. Parte general (trad. Gladys Romero, Navarra, Cizur Menor/Thomson/Civitas).

TARuffo, Michele (2002): Sui Confini (Bologna, Il Molino).

Tiedemann, Klaus (1991): "Constitución y derecho penal", Revista Española de Derecho Constitucional, no 33: pp. 145-171.

Tonini, Paolo (2003): Manuale di procedura penale (Milano, Giuffrè Editore, quinta edizione).

Vera SÁnchez, Juan (2015): "Algunas variables Político-Criminales del proceso penal", Revista de Estudios penales y Criminológicos, 35, Universidad Santiago de Compostela: pp.1-57. 
Vera SÁnchez, Juan (2016), "La persona jurídica ante el proceso penal", en Mir Puig, Santiago/Corcoy Bidasolo, Mirentxu (dirs): Manual de Derecho penal, Económico y de la empresa (Valencia, Tirant lo Blanch) pp 201-242.

Weinberger, Ota (1981): Normentheorie als Grundlage der Jurisprudenz und Ethik. (Berlin, Duncker \& Humblot).

Wessels, Johannes (1980): Derecho penal. Parte General (trad. Conrado Finzi, Buenos Aires, Depalma).

Welzel, Hans (1976): Derecho penal alemán. Parte general (trad. Juan Bustos Ramírez, Santiago, Editorial Jurídica de Chile. segunda edición).

Wolter, Jürgen (2004): "Estudio sobre la dogmática y la ordenación de las causas materiales de exclusión, del sobreseimiento del proceso, de la renuncia a la pena y de la atenuación de la misma. Estructuras de un sistema integral que abarque el delito, el proceso penal y la determinación de la pena”, en Wolter, Jürgen/Freund, Georg (eds): El sistema integral del derecho penal (Barcelona, Marcial Pons.) pp. 31-90.

\section{NORMAS CITADAS}

Ley No 19.696 (12/10/2000), Establece Código Procesal Penal

Ley Orgánica No5/2010 (22/06/2010), por la que se modifica la Ley Orgánica 10/1995, de 23 de noviembre, del Código Penal. España.

Ley No 37/2011 (10/10/2011), de medidas de agilización procesal. España.

Ley Orgánica No13/2015 (05/10/2015), de modificación de la Ley de Enjuiciamiento Criminal para el fortalecimiento de las garantías procesales y la regulación de las medidas de investigación tecnológica. España.

\section{JURISPRUDENCIA CITADA}

Ministerio Público c/Fernando Alexis Martínez (2007): Tribunal de Juicio Oral en lo Penal de San Antonio, 28 de marzo de 2007 Procedimiento Ordinario) Rit 12-2007.

Ministerio Público c/Sebastián Aarón Alfaro M (2008): Tribunal de Juicio Oral en lo Penal de Antofagasta, 27 de julio, 2008 (Procedimiento Ordinario), Rit 113-2008.

Ministerio Público c/Miguel Esteban Villalobos P. (2008): Tribunal del Juicio Oral en lo Penal de Concepción, 7 de septiembre de 2008 Procedimiento Ordinario) Rit 2902008. 
